\title{
Análise de um modelo para a formação de professores e suas aplicações ${ }^{1}$
}

\section{Analysis of teachers' formation model with applications}

\author{
Edna Maria Querido de Oliveira Chamon ${ }^{2}$ \\ Adriane de Castro Menezes Sales ${ }^{3}$
}

\begin{abstract}
RESUMO
O objetivo deste artigo é aplicar um modelo de análise aos processos de formação docente. Este modelo é construído a partir de três polos - o conhecimento, a situação e o sujeito -, que definem três lógicas de formação: epistêmica, socioprofissional e psicológica. O modelo foi aplicado em dois estudos, uma formação continuada e uma formação inicial. Para o primeiro estudo, 189 professores da rede estadual de ensino do Estado de São Paulo avaliaram a formação que cursavam. Para o segundo estudo, 964 alunos do curso de Pedagogia de uma instituição do Estado do Pará responderam a um questionário sobre a formação recebida. Os resultados obtidos mostraram que: 1) a formação ofertada no primeiro estudo relaciona-se fundamentalmente ao polo socioprofissional do modelo; 2) a formação do segundo estudo relaciona-se aos polos socioprofissional e epistêmico.

Palavras-chave: formação de professores; modelo de formação; profissão docente.
\end{abstract}

1 Este trabalho contou com apoio financeiro do Conselho Nacional de Desenvolvimento Científico e Tecnológico (CNPq).

2 Doutorado em Psicologia - Université de Toulouse II (Le Mirail), pós-doutorado em Educação na Universidade Estadual de Campinas (UNICAMP). Atualmente é professora assistente doutora da Universidade de Taubaté (UNITAU), Brasil. E-mail: edna.chamon@gmail.com

3 Mestre em Gestão e Desenvolvimento Regional pela UNITAU. Atualmente, Coordenadora de Pós-graduação da Universidade Estadual Vale do Acaraú, no Pará, e Faculdade Ipiranga, Brasil. E-mail: ammsalles@gmail.com 


\begin{abstract}
This paper proposes an analytical model to the teacher education process. The theoretical framework supporting our analysis is based on an analytical model, composed by conceptual, psychological, and professional elements, which guides the education design. This model was applied to two study cases. In the first one, 189 teachers from Sao Paulo State evaluated a continuing education program. In the second study, an education undergraduate course was evaluated by 964 students. Results showed that: 1) for the first case, the education program was mainly related to the professional axis of the model; 2) for the second case, the undergraduate course was related to both axes, professional and conceptual.

Keywords: teachers' formation; education model; teaching profession.
\end{abstract}

\title{
Introdução
}

Toda formação de professores procura, em alguma medida, implementar dinâmicas de preparação, de revitalização e de aprofundamento de conhecimentos necessários à prática docente, além de discutir intervenções inovadoras no sistema educativo. Tais ideais, embora não excludentes, não são facilmente conciliáveis, dada a profusão e diversidade de interesses, objetivos e agentes envolvidos no processo (PARDAL; MARTINS, 2005).

Apresentamos aqui um modelo analítico para o processo de formação, juntamente com exemplos de sua aplicação. O modelo foi proposto originalmente por Fabre (1994) para o quadro de uma formação geral e adaptado aqui para situações específicas de professores.

Paralelamente ao modelo, apresenta-se a avaliação de dois processos de formação, uma inicial e outra continuada, de professores, do ponto de vista dos formandos. Esses estudos - que empregam o triângulo da formação como guia de leitura - sugerem o potencial do uso do modelo na avaliação de programas de formação.

\section{Pensar a Formação}

Silva (2000) caracteriza quatro campos semânticos da formação: educação, ensino, instrução e formação propriamente dita. Os quatro campos, em diferentes 
proporções, remetem a significados individuais e institucionais, representando ora a formação do indivíduo ou as relações entre indivíduos, ora os sistemas abstratos ou institucionais de formação.

A educação remete à ideia de nível ou de elevação de nível. Trata-se de uma significação não específica que designa tanto um desenvolvimento intelectual quanto físico ou moral.

O ensino é principalmente ligado ao lado operacional do método e ao aspecto institucional da atividade. $\mathrm{O}$ ensino ocorre num quadro institucional, com métodos bem definidos e profissionais qualificados. Ensinar está ligado a aprender, a explicar, a mostrar e demonstrar.

A instrução refere-se aos conteúdos que devem ser transmitidos. Trata-se de transmitir informações a fim de desenvolver o espírito e o intelecto. É nesse sentido que falamos de uma pessoa instruída.

A formação evoca o ato de dar forma, isto é, transformar o indivíduo integralmente. Mais do que métodos ou conhecimentos, a formação designa uma mudança qualitativa do indivíduo, que ocorre simultaneamente em diferentes dimensões: psicológica, cognitiva, social.

Dessa forma, podemos agrupar os vários sentidos de formar sob três orientações:

1. transmitir conhecimentos;

2. modelar a personalidade;

3. integrar o conhecimento à prática.

Essas três orientações indicam três lógicas de formação: a lógica didática (ou epistêmica) dos conteúdos e dos métodos; a lógica psicológica da evolução do indivíduo, e a lógica socioeconômica, da adaptação.

Essas lógicas estão sempre presentes em uma formação concreta, pois ela ocorre em um determinado contexto, ao mesmo tempo em que busca a transmissão de um saber e diz respeito a indivíduos que aprendem. A predominância de uma dessas lógicas define uma configuração particular de formação. Uma formação profissional (com seu caráter de preparação para uma atividade), uma formação psicológica (com seu caráter de desenvolvimento pessoal) ou uma formação epistêmica (com seu caráter de construção do conhecimento). Para cada configuração há uma lógica dominante (que define a configuração), uma lógica dominada (utilizada para atingir o objetivo projetado) e uma lógica marginal (negligenciada na construção da formação mas eventualmente presente na ação ou no produto). Por exemplo, uma formação profissional se constrói em torno de uma lógica socioeconômica, utilizando métodos e conteúdos. O desenvolvimento pessoal, que tem um papel marginal, está presente, embora talvez de maneira 
reduzida, no indivíduo formado. Já uma formação acadêmica stricto sensu, como a preparação de um doutorado, articula as lógicas epistêmica e psicológica, marginalizando a lógica socioeconômica, ainda que esta esteja presente no leque de atividades para as quais o indivíduo se dirige uma vez formado.

\section{Um modelo de formação}

O triângulo da formação, mostrado na Figura 1, sintetiza as três configurações e suas relações com as lógicas de formação.

pólo socioprofissional

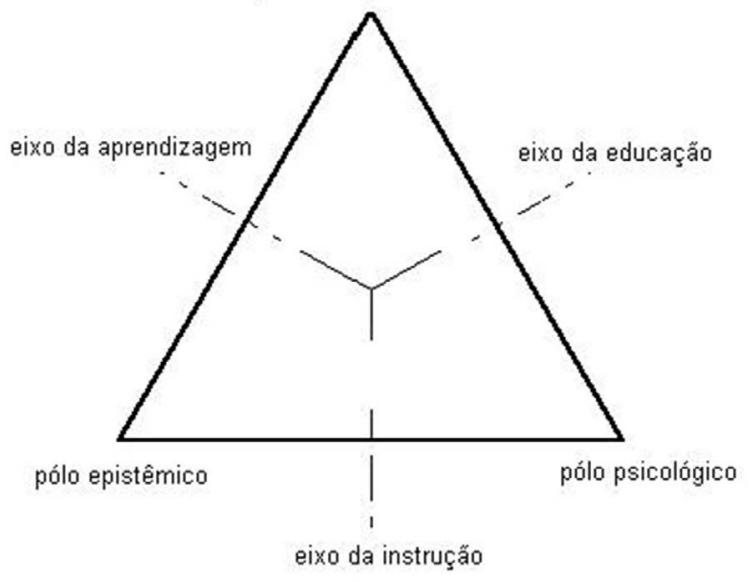

Figura 1- O triângulo da formação (FABRE, 1994, p. 26)

Esse triângulo representa um modelo teórico que permite que se pense a formação a partir de seus três elementos, de suas articulações e de suas dominâncias. Em particular, ele permite analisar o processo de formação - inicial e continuada - de professores.

\section{As lógicas da formação}

Na base de toda formação podemos encontrar três polos aos quais ela se relaciona: o conhecimento, a situação e o sujeito. Sempre presentes, ainda que em níveis de ativação diferentes, eles implicam três lógicas diferentes: epistêmica, socioprofissional e psicológica. 
A lógica epistêmica é a dos conteúdos e métodos, é a lógica do conhecimento. É a "formação em" alguma coisa, a formação em pedagogia, por exemplo. A especificidade dessa lógica vem da relação entre o conhecimento e os problemas que lhe dão sentido. A dialética teoria/prática, que é a dialética saber/saber-fazer, está na base de uma lógica de formação epistêmica.

A lógica socioeconômica é aquela da adaptação aos contextos culturais ou profissionais. É a lógica das primeiras definições de uma formação profissional: é a "formação para" alguma coisa, tendo em vista uma adaptação mais ou menos ampla à sociedade. No sentido de uma adaptação ao posto de trabalho, essa lógica reflete o modelo taylorista, com seus princípios de decomposição de tarefas e separação dos trabalhos de concepção e execução. No sentido de reprodução social, de acordo com Bourdieu e Passeron (1970), ela reflete os objetivos político-econômicos da classe dominante.

Finalmente, a lógica psicológica é aquela da evolução do indivíduo, da mudança qualitativa. A mudança individual é pensada em termos psíquicos, em termos de crise, ruptura e superação. É a lógica de formação que leva o indivíduo a se questionar, a modificar suas práticas e seus modos de relação com o mundo. Em história, por exemplo, essa mudança qualitativa pode corresponder à passagem da descrição dos fatos históricos à análise das estruturas. Em psicologia do desenvolvimento, essa mudança corresponde à constatação de que o conhecimento é construído pela criança muito mais do que lhe é imposto externamente. É a "formação de si mesmo". Mais do que conteúdos científicos, novas maneiras de olhar a realidade são aprendidas.

\section{As problemáticas da formação}

As problemáticas da formação repousam nas diferentes articulações das três lógicas analisadas anteriormente. Essas articulações constroem-se em torno de uma lógica dominante e de uma lógica dominada, com a marginalização da terceira lógica. Assim, uma modalidade de formação será definida por um problema fundamental de articulação entre dois polos e será caracterizada pelos questionamentos do polo negligenciado. Teremos, então, não apenas uma, mas três problemáticas possíveis, em função das combinações entre os polos da formação (ALTET; FABRE, 1994):

- a problemática de articulação entre valor epistemológico e desenvolvimento pessoal;

- a problemática de articulação entre desenvolvimento pessoal e inserção socioprofissional; e,

- a problemática de articulação entre valor epistemológico e inserção socioprofissional. 
A formação de professores se inscreve em cada uma dessas problemáticas, mas a cada vez ela adquire um sentido diferente. Ela pode representar a formação no sentido de transmissão de informações, de orientação científica (formação no sentido de instrução). É a abordagem tradicional do problema, defendida por vários pesquisadores (CARVALHO; SIMÕES, 2002), e baseia-se na ideia da ampla difusão do conhecimento como chave para o desenvolvimento futuro. Apoia-se frequentemente no uso de novas tecnologias para a transmissão de informações, habilidades e atitudes. Trata-se, entretanto, e essa é sua limitação fundamental, de uma estratégia proposta de forma vertical, onde a formação é vista como um produto, baseada em pacotes de treinamento.

Por outro lado, a formação de professores pode ser vista em um sentido mais amplo de reflexão e questionamento, próxima da formação no sentido de transformação da pessoa. É uma abordagem centrada no professor como sujeito, buscando a formação do professor reflexivo (SCHÖN, 1995), tanto em relação ao seu saber (teórico), como seu saber-fazer (prático). Sua limitação fundamental é não integrar o contexto sociopolítico mais amplo, não contemplando a escola e seus projetos, restringindo-se ao professor e sua atividade em sala de aula.

Finalmente, a formação docente pode contemplar processos de adaptação socioprofissional, de caráter mais individual, ou de adaptação ao projeto da escola, de caráter mais coletivo. É a formação vista em seu aspecto de ensino. Essa abordagem procura preparar o professor para transformações institucionais. Normalmente associada à socialização profissional, com aspectos de carreira e integração ao grupo, essa visão tende a marginalizar transformações pessoais mais globais.

\section{- A formação como um eixo de instrução}

O primeiro contexto no qual a formação pode se inscrever diz respeito à articulação entre um valor epistêmico e um valor formador de concepções do saber (articulação entre os polos epistêmico e psicológico). Nessa óptica, a função da formação é modificar as relações entre o sujeito e o conhecimento: passa-se da transmissão do conhecimento por um formador, a uma produção ativa desse conhecimento por parte do sujeito. Trata-se de construir uma nova representação do conhecimento como um processo de elaboração, em movimento, como construção inacabada. A atividade de pesquisa, que muitas vezes está associada à formação inicial (trabalhos de conclusão de curso) e à formação continuada (cursos de pós-graduação), caracteriza muito bem essa problemática de formação. Essa atividade se exerce em dois níveis (BEILLEROT, apud ALTET; FABRE, 1994): 
- o nível das condições mínimas da pesquisa: produção de novos conhecimentos (polo epistêmico), método de investigação rigoroso e comunicação de resultados;

- o nível das características suplementares: dimensão crítica ou reflexiva (polo psicológico), sistematização da coleta de dados e quadro teórico interpretativo.

É preciso observar, entretanto, que o conhecimento científico por si só não tem valor formador mais amplo. A busca de conhecimento que comporta uma componente moral orientadora da ação é uma concepção grega, que não é mais corrente hoje em dia. O modelo de conhecimento atual, que tem suas raízes no século XII, com a criação da Universidade no Ocidente, é historicamente marcado por um duplo (e, num certo sentido, paradoxal) movimento: por um lado, a fragmentação do conhecimento, com sua organização em áreas, disciplinas e especialidades; por outro, a reunião desses "fragmentos" num espaço institucional comum - a Universidade - numa tentativa de união de suas diversas e dispersas partes (DOMINGUES et al., 2001).

O conhecimento, assim, se caracteriza pela especialização e pela fragmentação, pela mecanização do pensamento e por uma planificação do tipo econômica (MATOS, 2001), que são incompatíveis com a formação individual em sentido amplo. Assim, a formação - dentro da problemática apresentada exige a articulação com o polo psicológico. Não há, entretanto, a preocupação com aspectos sociais ou profissionais.

\section{- A formação como um eixo de educação}

Esta problemática diz respeito a uma transformação do sujeito buscando uma adaptação social, uma equilibração no sentido piagetiano. A formação docente pode igualmente se inscrever nessa problemática de articulação entre desenvolvimento pessoal e adaptação socioprofissional, aproximando-se, nesse caso, de uma formação filosófica, na medida em que implica em uma atitude de questionamento, de investigação e de reflexão. $\mathrm{O}$ valor pedagógico da formação aqui é o do assombro e do abalo, do questionamento. A articulação com o polo socioprofissional vem do questionamento de si mesmo, que faz parte de um movimento de construção identitária profissional. São importantes, nessa formação, o trabalho em equipe e as trocas entre os participantes. A transmissão de conhecimentos é menos importante aqui do que a reflexão sobre o saber e o saber-fazer do professor. 


\section{- A formação como um eixo de aprendizagem}

O problema fundamental aqui é o da formação profissional: como uma formação pode ser ao mesmo tempo válida no plano epistemológico e útil no plano socioprofissional?

A ideia inicial é a de formar para funções precisas, ligadas às novas atividades que surgem com as mudanças na profissão ou na estrutura da instituição. Trata-se de um aprendizado para resolução de problemas práticos, que um quadro de conhecimentos teóricos mais amplo permite tratar. Não há, nesse caso, questionamento do indivíduo ou do sistema, buscando-se, ao contrário, uma adaptação entre o indivíduo e suas tarefas. Essas tarefas podem representar tanto a atividade quotidiana do indivíduo, para a qual ele se recicla, quanto uma evolução profissional dentro sistema, para a qual ele se prepara, como ainda uma adaptação a um novo projeto institucional, do qual ele participa.

Na prática, uma formação docente privilegiará uma dessas problemáticas, mantendo, entretanto, ainda que marginalmente, perspectivas do polo marginalizado. Os modos tradicionais de formação insistiram fundamentalmente nas problemáticas centradas no polo epistêmico - que corresponde a uma lógica técnica - negligenciando a função crítico-reflexiva da escola. Essa função, entretanto, sempre esteve presente na atividade teórica acadêmica (os trabalhos de pesquisa ligados à educação) e, ainda que de forma dispersa e difusa, nas práticas docentes (devido ao espaço imediato de autonomia que o professor mantém em sala de aula).

\section{A Pesquisa}

Este trabalho apresenta dois estudos nos quais o modelo de formação é utilizado como grade de leitura para análise de processos de formação docente. Em ambos os estudos, buscou-se refletir sobre o formato e a lógica dessa formação.

\section{A formação PEC (CHAMON, 2003)}

O primeiro estudo trata de docentes efetivos PEB I (Professor do Ensino Básico I) do Estado de São Paulo, que possuíam formação em nível médio (Habilitação Magistério), aos quais foi proposto um "programa experimental de licenciatura plena [...] fornecendo diploma correspondente expedido pelas instituições de ensino superior contratadas para este fim" (PEC, 2001, p. 12).

A formação, denominada PEC - Programa de Educação Continuada, destinou-se a professores com, no mínimo, dez anos de docência e se desenvolveu 
em paralelo com o trabalho docente nas escolas de origem desses professores. $\mathrm{O}$ ensino era presencial, com apoio expressivo de mídias interativas, organizado na forma de módulos. Os CEFAM (Centros Específicos de Formação e Aperfeiçoamento do Magistério) forneceram a infraestrutura física e de comunicação (multimídia) para o desenvolvimento do programa.

A coleta de dados foi estruturada a partir de um questionário contendo questões fechadas sociodemográficas para caracterização da amostra; questões avaliativas da formação e questões relativas à profissão docente e à atividade do professor. Uma amostra de conveniência, representada pelos alunos-professores que seguiam a formação foi considerada para essa pesquisa. Foram aplicados 250 questionários, dos quais 189 retornaram e foram considerados completos e em condições de tratamento, o que representa cerca de $75 \%$ de aproveitamento. Os questionários foram aplicados no final do período de formação, a fim de permitir uma melhor avaliação da mesma.

\section{Formação inicial em pedagogia (SALES, 2008)}

O segundo estudo é uma análise de processos de formação docente no quadro de um curso de graduação em Pedagogia de uma instituição privada de ensino superior no município de Belém/PA. Uma combinatória de técnicas quantitativas e qualitativas foi aplicada, sendo que apenas a análise quantitativa, baseada em questionário, será apresentada neste trabalho. A coleta de dados empregou um questionário composto de 99 questões divididas em cinco categorias de análise: descrição sociodemográfica; ser professor; formação; prática; escolha profissional. Serão apresentadas aqui a caracterização sociodemográfica da amostra e a categoria "formação". A amostra estudada constou de 964 sujeitos, de um universo de 2.215 alunos regularmente inscritos na formação, cursando do primeiro ao quinto semestre durante o ano letivo de 2006.

\section{Os Resultados}

\section{Primeiro estudo: A Formação PEC (CHAMON, 2003)}

Apresentamos a seguir a análise das estatísticas descritivas da amostra. $\mathrm{O}$ objetivo é caracterizar o grupo de alunos-professores por variável representativa do questionário. Em seguida, a análise das questões avaliativas permitirá a caracterização da formação nos termos propostos pelo modelo de Fabre, exposto anteriormente. 
Caracterização da amostra

Sexo

TABELA 1- DISTRIBUIÇÃO DA AMOSTRA POR SEXO

\begin{tabular}{|l|r|r||}
\hline \multicolumn{3}{|c|}{ SEXO } \\
\hline Qual é o seu sexo ? \\
\hline Não resposta & 1 & $0,5 \%$ \\
\hline Masculino & 3 & $1,6 \%$ \\
\hline Feminino & 185 & $97,9 \%$ \\
\hline Total & 189 & $100,0 \%$ \\
\hline
\end{tabular}

Como pode ser visto na tabela acima, a constituição do grupo tem forte representação feminina, o que é corroborado por várias outras pesquisas. A feminização da profissão docente é fato conhecido. A educação, na realidade, é um dos poucos setores onde as mulheres "dominam” há já algum tempo.

\section{Idade}

A média de idade dos indivíduos é relativamente alta (45 anos e meio), tendo a maioria idade variando entre 38 e 52 anos. Entretanto, deve-se considerar que um dos critérios para admissão no programa de formação era um mínimo de dez anos de docência e que o tempo médio de docência da amostra é de cerca de 18 anos, o que explica uma média de idade elevada.

TABELA 2- DISTRIBUIÇÃO DA AMOSTRA POR IDADE

\begin{tabular}{||r|r|r|}
\hline \multicolumn{3}{|c|}{ IDADE } \\
\hline Qual é a sua idade em anos completos? \\
\hline Não resposta & 2 & $1,1 \%$ \\
\hline Menos de 35 & 11 & $5,8 \%$ \\
\hline De 35 a 39 & 35 & $18,5 \%$ \\
\hline De 40 a 44 & 30 & $15,9 \%$ \\
\hline De 45 a 49 & 49 & $25,9 \%$ \\
\hline De 50 a 54 & 46 & $24,3 \%$ \\
\hline 55 e mais & 16 & $8,5 \%$ \\
\hline Total & 189 & $100,0 \%$ \\
\hline
\end{tabular}


Avaliação da formação

Satisfação com a formação

As respostas indicam que, mesmo se alguns consideram que a formação não é diretamente aplicável em sala de aula (como sugere a questão sobre aplicação da formação - ver análise adiante), ela não deixa de satisfazer às expectativas dos alunos-professores.

TABELA 3- SATISFAÇÃO COM O PROGRAMA DE FORMAÇÃO

\begin{tabular}{l} 
SATISF_PEC \\
\begin{tabular}{|l|r|r|} 
Você está satisfeito(a) com a formação que \\
escolheu? \\
\hline Totalmente satisfeito(a) & 77 & $40,7 \%$ \\
\hline Muito satisfeito(a) & 52 & $27,5 \%$ \\
\hline Satisfeito(a) & 57 & $30,2 \%$ \\
\hline Pouco satisfeito(a) & 3 & $1,6 \%$ \\
\hline Nada satisfeito(a) & 0 & $0,0 \%$ \\
\hline Total & 189 & $100,0 \%$ \\
\hline
\end{tabular} \\
\hline
\end{tabular}

Formação e prática docente

As respostas a essa questão levam a crer numa transposição da formação em prática pedagógica.

TABELA 4- APROVEITAMENTO DA FORMAÇÃO NA PRÁTICA PEDAGÓGICA

\begin{tabular}{|l|r|r|}
\hline \multicolumn{3}{|c|}{ APROVEITA_PEC } \\
\begin{tabular}{|l|r|r|}
\hline O que você aprendeu no PEC tem sido \\
aproveitado em sua prática docente?
\end{tabular} \\
\hline Não resposta & 3 & $1,6 \%$ \\
\hline Muito & 167 & $88,4 \%$ \\
\hline Um pouco & 19 & $10,1 \%$ \\
\hline Muito pouco & 0 & $0,0 \%$ \\
\hline Quase nada & 0 & $0,0 \%$ \\
\hline Nada & 0 & $0,0 \%$ \\
\hline Total & 189 & $100,0 \%$ \\
\hline
\end{tabular}


Percebe-se aqui a inscrição da formação em uma problemática distinta da tradicional. De fato, é usual construir uma formação em torno da lógica epistêmica, privilegiando uma problemática de instrução, buscando a transmissão de conhecimentos aos alunos. Os resultados dessa questão parecem sugerir uma problemática de aprendizagem, construída ainda sobre a lógica epistêmica, mas buscando as aplicações práticas e a inserção do conhecimento no polo socioprofissional.

\section{Monografia}

Os alunos-professores afirmam que o trabalho de monografia foi um momento de aprendizado, ainda que tenham tido dificuldades na sua elaboração. Quase $50 \%$ da amostra declara ter feito o trabalho sozinho ou com ajuda de colegas, o que indica a percepção de um orientador de monografia ausente.

TABELA 5 - CONDIÇÕES DE DESENVOLVIMENTO DA MONOGRAFIA

\begin{tabular}{|l|r|r|}
\hline \multicolumn{3}{|c|}{ MONOGRAFIA } \\
\begin{tabular}{|l|r|} 
O seu trabalho de monografia foi feito (você pode assinalar várias \\
opços)
\end{tabular} \\
\hline Não resposta & 1 & $0,2 \%$ \\
\hline Em um ambiente prazeroso & 33 & $5,5 \%$ \\
\hline Em um clima angustiante & 132 & $22,0 \%$ \\
\hline Com muitas dificuldades & 171 & $28,5 \%$ \\
\hline Foi um momento de aprendizado & 91 & $15,2 \%$ \\
\hline Fiz sozinho(a) & 89 & $14,8 \%$ \\
\hline Contei com a ajuda dos colegas & 44 & $7,3 \%$ \\
\hline Com dificuldades financeiras e materiais & 600 & $100,0 \%$ \\
\hline Total &
\end{tabular}

A atividade de pesquisa, representada pelo desenvolvimento de uma monografia de final de curso, se enquadra claramente dentro da problemática da instrução, articulando os polos epistêmico e psicológico, como já foi discutido. Entretanto, as características da monografia proposta na formação, na qual os alunos-professores trabalharam temas de seu interesse ligados a seu universo de docência, podem também inscrever a formação dentro da problemática da aprendizagem. De fato, isso ocorre quando a pesquisa tem um caráter finalista, sendo guiada pela resolução de um problema prático. Nesse caso, o valor formador da monografia vem de uma transferência de métodos e técnicas científicas (polo epistêmico) para o domínio profissional. 
Expectativas após a formação

Neste item os alunos-professores descrevem suas expectativas em relação à sua vida pessoal e profissional após a formação. A grande maioria acredita que utilizará seus conhecimentos e capacidade de reflexão na atividade pedagógica. Afirmam também ter mudado sua visão de mundo, ganhando segurança e autonomia em sala de aula. As preocupações de caráter mais material (futuro estável, aumento salarial) são menos ressaltadas. Finalmente, o ganho de prestígio recebeu muito pouca atenção, talvez pelo fato de que o curso superior já não é mais um fator de destaque no mundo dos professores, mas passou a fazer parte das condições mínimas para exercício da profissão.

TABELA 6- EXPECTATIVA FUTURA

\begin{tabular}{|l|r|r|}
\hline \multicolumn{3}{|c|}{ APÓS_PEC } \\
\hline Após a con clusão do PEC você acredita que (você pode assinalar mais de uma alternativa) \\
\hline Terá um futuro mais estável & 49 & $9,4 \%$ \\
\hline Ganhará mais dinheiro & 44 & $8,4 \%$ \\
\hline Terá mais auton omia em sala de aula & 115 & $22,0 \%$ \\
\hline Poderá utilizar mais sua capacidade intelectual para elaborar suas aulas & 167 & $31,9 \%$ \\
\hline Ganhará status (prestigio) & 18 & $3,4 \%$ \\
\hline Terá mudado sua visão do mundo & 130 & $24,9 \%$ \\
\hline Total & 523 & $\mathbf{1 0 0 , 0 \%}$ \\
\hline
\end{tabular}

Apresentam-se aqui duas problemáticas, ambas centradas no polo socioprofissional: 1) a associação da formação com a elaboração de aulas indica a articulação com o polo epistêmico, dentro da problemática de aprendizagem; e 2) a associação com a mudança na visão de mundo indica, embora de forma tênue, a articulação com o polo psicológico, dentro da problemática de educação.

\section{Segundo estudo: Formação inicial em pedagogia (SALES, 2008)}

Da mesma forma que no estudo precedente, apresentamos a seguir as estatísticas descritivas da amostra. Em seguida, será realizada a análise da formação nos termos propostos pelo modelo de Fabre. 


\section{Caracterização da amostra}

Sexo

Como pode ser visto na Figura 2, a constituição do grupo novamente tem forte representação feminina ( $94,3 \%$ da amostra).

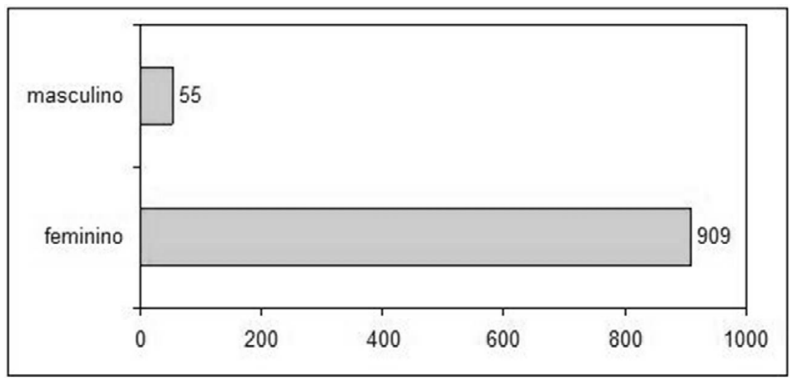

Figura 2- Distribuição da amostra por sexo

\section{Idade}

A média de idade dos indivíduos é de 31 anos, mais baixa que a da amostra do estudo anterior, mas ainda alta. Em muitos casos, aqui, trata-se de estudantes que já atuam como docentes e que buscam a conclusão do programa de graduação. A maioria tem idade variando entre 20 e 39 anos.

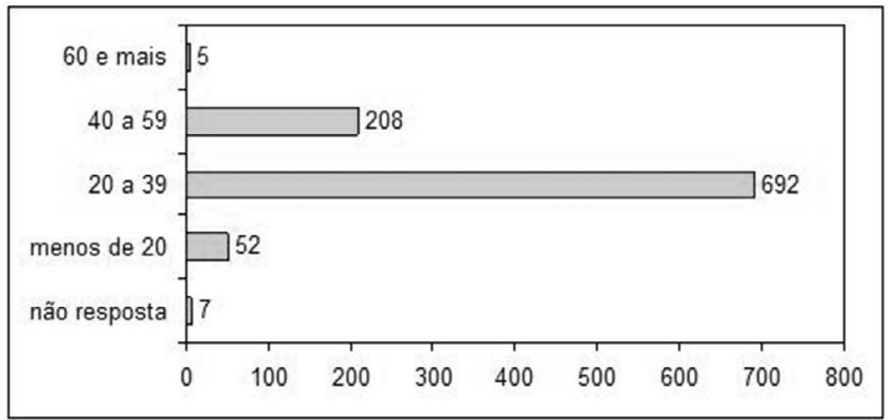

Figura 3- Distribuição da amostra por idade

Avaliação da formação

Serão descritos aqui os resultados relativos à percepção dos sujeitos quanto aos aspectos curriculares e didático-metodológicos da formação, que consti- 
tuem a dimensão "Proposta Institucional", e quanto aos aspectos referentes à organização e ao material didático, que constituem a dimensão "Organização e Apoio Didático". Esses resultados serão analisados à luz do modelo de formação apresentado.

\section{Proposta Institucional}

Nesta categoria, os dados coletados referem-se aos aspectos ligados às questões curriculares e didático-pedagógicas, o que pode ser observado na Figura 4.

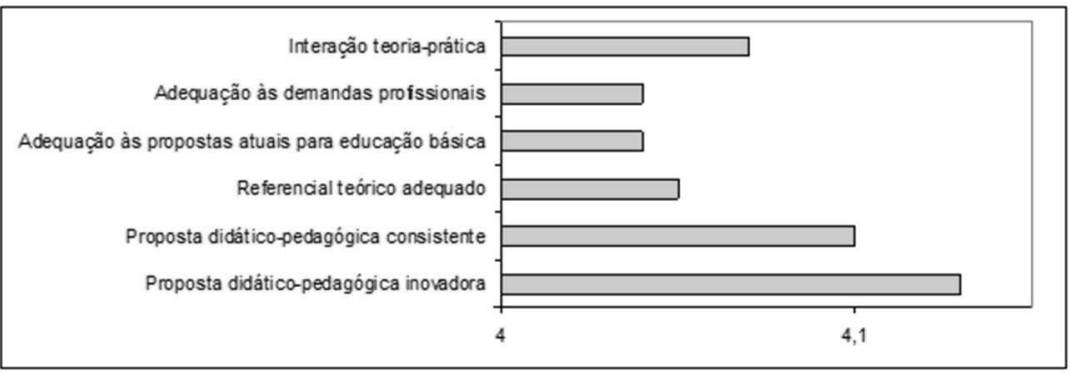

Figura 4- Proposta institucional

Em relação ao modelo de formação adotado, os resultados apresentados denotam que a formação prioriza o polo epistêmico e o socioprofissional, determinando que a proposta de formação estudada está centrada no eixo da aprendizagem.

De acordo com a avaliação da estrutura curricular, o curso privilegia as questões relacionadas à preparação dos sujeitos para o atendimento das demandas profissionais. Em relação à preponderância dos polos da formação, observa-se que os itens referentes ao caráter inovador da proposta; à adequação da estrutura curricular; e, ao atendimento das atuais demandas profissionais estabelecem estreita ligação com o polo socioprofissional. Porém, os itens com médias mais expressivas são ligadas ao polo epistêmico: proposta didático-pedagógica consistente; referencial teórico adequado para a formação; e, estrutura flexível e que favorece a integração teoria/prática.

Portanto, nesta categoria, o polo dominante é o epistêmico, o dominado é o socioprofissional, enquanto o polo psicológico, que diz respeito à transformação do indivíduo, é notadamente negligenciado nesse modelo de formação. 


\section{Organização e Apoio Didático}

Nesta categoria, os dados coletados referem-se aos aspectos ligados às questões de organização do currículo e da proposta em geral, bem como de recursos didáticos disponíveis, o que pode ser observado na Figura 5.

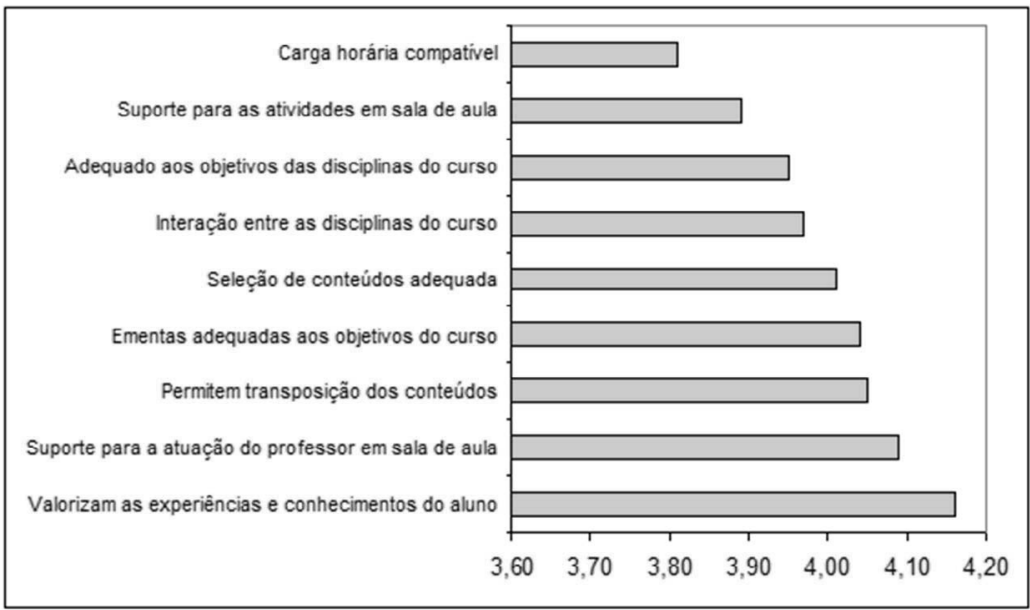

Figura 5- Organização e apoio didático

Os resultados obtidos indicam uma formação construída, na sua organização curricular e recursos didáticos, para o atendimento das demandas atuais do sistema educacional, que se caracteriza pela dominante da aprendizagem (articulação epistêmica-socioprofissional).

Isso pode ser notado na análise das respostas ao questionário. Nas questões referentes aos materiais didáticos, a avaliação dos sujeitos os aponta como ligados ao próprio exercício profissional (recurso para atuação em sala de aula). Nas questões referentes às disciplinas, os sujeitos indicam que a formação valoriza as experiências e os saberes discentes, o que facilita a compreensão dos conteúdos e sua transposição didática.

\section{Considerações Finais}

Dentre as diversas visões possíveis sobre a formação de professores desde as de caráter mais instrumental, centradas no desenvolvimento do sistema educativo, até aquelas de caráter emancipador, que buscam o resgate identitário 
do professor - expusemos aqui um modelo analítico, resumido no triângulo da formação, que procura captar a lógica da construção de uma formação a partir de seus objetivos relativos ao professor.

As três lógicas apresentadas, bem como suas possíveis articulações, buscam mapear a dinâmica da formação em termos de conteúdos transmitidos (lógica epistêmica), adaptação à atividade profissional (lógica socioprofissional) e evolução individual (lógica psicológica).

Os três polos e problemáticas do modelo apresentado devem ser considerados tipos ideais, no sentido weberiano, na medida em que toda formação contempla, em maior ou menor grau, todas as facetas do modelo.

Isso pode ser percebido a partir da análise dos dados empíricos dos estudos apresentados, que abordam formações concretas e específicas de professores. Mesmo levando em consideração as limitações próprias ao método, a avaliação dos resultados obtidos mostra a utilidade do modelo analítico apresentado. Em particular, os resultados relativos às condições de desenvolvimento da monografia (Tabela 8), às expectativas futuras dos alunos-professores (Tabela 9), no primeiro estudo, e à proposta institucional (Figura 5), no segundo estudo, indicam a presença de dinâmicas de instrução, aprendizagem e educação - no sentido definido neste trabalho - ainda que tais dinâmicas não estivessem propositadamente no desenho original da formação.

O modelo do triângulo da formação nos parece interessante tanto como possibilidade de pensar a posteriori uma formação quanto como instrumento para conceber essa formação. Ele não é, entretanto, completo e isento de críticas. Particularmente, é notável a ausência de uma análise de aspectos políticos e sociais no modelo. Ele é muito mais centrado no indivíduo e nos objetivos da formação relativos a ele. Ainda assim, a problemática da educação, que articula os polos psicológico e socioprofissional, pode servir de base para o estudo de dispositivos de formação, aos quais está inerente uma racionalidade crítica (SILVA, 2000).

\section{REFERÊNCIAS}

ALTET, M.; FABRE, M. Logiques et problématiques d'articulation formation/recherche dans les dispositifs de professionnalisation. Recherche et Formation. Lyon, n. 17, p. 77-92, 1994.

BOURDIEU, P.; PASSERON, J.-C. La reproduction. Eléments pour une théorie du 
système d'enseignement. Paris: Minuit, 1970.

CARVALHO, J. M.; SIMÕES, R. H. S. O processo de formação continuada de professores: uma construção estratégico-conceitual expressa nos periódicos. In: ANDRÉ, M. E. D. A. de (org.). Formação de professores no Brasil (1990-1998). Brasília: MEC/Inep/ Comped, 2002, p. 171-184.

CHAMON, E. M. Q. O. Formação e (re)construção identitária: estudo das memórias de professores do ensino básico inscritos em um programa de formação continuada. Trabalho de Pós-doutorado, Faculdade de Educação, Universidade Estadual de Campinas, Campinas, 2003.

DOMINGUES, I. et al. Um novo olhar sobre o conhecimento. In: DOMINGUES, I. (org.). Conhecimento e transdisciplinaridade. Belo Horizonte: UFMG/IEAT, 2001, p. 13-27.

FABRE, M. Penser la formation. Paris: Presses Universitaires de France, 1994.

MATOS, O. C. F. Ethos e amizade: a morada do homem. In: DOMINGUES, I. (org.). Conhecimento e transdisciplinaridade. Belo Horizonte: UFMG/IEAT, 2001, p. 59-72.

PARDAL, L. A.; MARTINS, A. M. Formação contínua de professores: concepções, processos e dinâmica profissional. Psicologia da Educação. São Paulo, n. 20, p. 103$117,2005$.

PEC. Programa de Educação Continuada. Formação de professores em exercício. Programa Especial de Formação de Professores de $1^{\text {a a }}$ 4 $^{\text {a }}$ Séries do Ensino Fundamental. São Paulo, 2001. 45 p.

SALES, A. C. M. Formação de professores em Belém do Pará: um estudo transversal sobre as diretrizes curriculares nacionais, saberes, práticas e a identidade profissional docente. Dissertação (Mestrado Profissional em Gestão e Desenvolvimento Regional) - Universidade de Taubaté, Taubaté 2008.

SCHÖN, D. Formar professores como profissionais reflexivos. In: NÓVOA, A. (coord.). Os professores e sua formação. Lisboa: Dom Quixote, 1995. p. 77-91.

SILVA, A. M. C. A formação contínua de professores: Uma reflexão sobre as práticas e as práticas de reflexão em formação. Educação e Sociedade. Campinas, n. 72, p. 89109, ago. 2000.

Texto recebido em 22 de janeiro de 2010.

Texto aprovado em 03 de março de 2010. 